\title{
Leiomyosarcoma of the corpus uteri
}

INSERM

\section{Source}

INSERM. (1999). Orphanet: an online rare disease and orphan drug data base. Leiomyosarcoma of the corpus uteri. ORPHA:213625

Leiomyosarcoma of the corpus uteri is a rare, malignant, mesenchymal tumor of smooth muscle origin characterized, histologically, by spindle and/or pleomorphic cells, often forming disorganized fascicles, with tumor cell necrosis and, macroscopically, by a large, soft, usually intramural mass with irregular borders and necrotic and hemorrhagic areas, located in the uterus. Presenting signs and symptoms typically include dysfunctional vaginal bleeding, vaginal discharge, palpable pelvic mass and/or pelvic pain/pressure. Changes in bowel habits, frequent or painful urination and hematuria may also be associated. 